\title{
Impact of Electron Energy and Dose on Particle Dynamics Imaging in the Scanning Electron Microscope
}

Yige Gao $^{1}$, Satyam Srivastava ${ }^{1}$, Paul Y. Kim² ${ }^{2}$ David A. Hoagland ${ }^{1}$, Thomas P. Russell ${ }^{1,2}$ and Alexander E. Ribbe ${ }^{1 *}$

1. Polymer Science \& Engineering Department, University of Massachusetts, Amherst, United States.

2. Materials Sciences Division, Lawrence Berkeley National Laboratory, Berkeley, California, United States.

* Corresponding author: aeribbe@umass.edu

Over past decades the majority of real-space nanoparticle (NP) dynamics measurements have been performed by Transmission Electron Microscopy (TEM) confining a liquid sample in various types of fluid cells, protecting the fluid from evaporation during imaging [1,2,3]. These TEM observations demonstrated that the electron interaction itself can extensively influence particle motion [4,5], but unfortunately one has limited control of beam energy, i.e. acceleration voltage, in TEM. In addition the interactions of the particles with the windows in these very thin cells can introduce artifact. Although Scanning Electron Microscopy (SEM) can be operated at much lower beam energies it has received little attention, since NP motion cannot be observed with a protective film that prevents evaporation of the vast majority of liquids under high vacuum conditions.

Ionic Liquids (IL) are a unique class of liquids that lack measurable vapor pressure and possess a wide range of physical properties, including to ability to vary the nature of the IL from hydrophobic to hydrophilic. The former affords the opportunity to use ILs under high vacuum conditions, thereby allows 'open' imaging by SEM. We recently demonstrated this method's ability to visualize 2dimensional Brownian NP motion [6] and the pair interaction potential between NPs [7]. In these experiments the acceleration voltage and beam current were critical parameters that could profoundly impact observed NP dynamics and, therefore, imaging parameters that must be tuned to minimize or eliminate impact on NP motion.

Here, rather than trying to eliminate beam sample-interactions, we present examples of electron beam induced NP motion and interactions. Besides beam current and acceleration voltage other imaging choices can influence the observed NP motion. For one, the conductivity of the used IL is important and for simplicity we restricted our experiment to [Emim][EtSO 4 , which appears fairly neutral under electron beam exposure. Studied systems include a variety of simple or core-shell poly(ethylene glycol) (PEG)-grafted gold and (spheres or rods) silica nanoparticles as well as gold-coated silica $\left(\mathrm{Au}_{\mathrm{c}} \mathrm{SiO}_{2 \mathrm{~s}}\right)$ or silica-coated gold $\left(\mathrm{SiO}_{2 \mathrm{c}} \mathrm{Au}_{\mathrm{s}}\right)$ NPs.

Below a threshold beam current (typically $<13$ pA) particle motions follow commonly applied physical principles [6,7] indicating negligible beam/sample interactions, a pattern that changes rapidly, once the beam current, is increased. We did not observe an obvious impact on particle motion when staying within an acceleration voltage range of $1 \mathrm{kV}$ to $3 \mathrm{kV}$. For the aforementioned $\mathrm{Au}_{\mathrm{c}} \mathrm{SiO}_{2 \mathrm{~s}}$ and $\mathrm{SiO}_{2 \mathrm{c}} \mathrm{Au}_{\mathrm{s}}$ nanoparticles, the particle/beam interactions created opposite response: exposed to higher electron doses, $\mathrm{Au}_{\mathrm{c}} \mathrm{SiO}_{2 \mathrm{~s}}$ showed long range attraction while $\mathrm{SiO}_{2 \mathrm{c}} \mathrm{Au}_{\mathrm{s}}$ showed repulsion resulting in disassembly of 2D aggregates. In a simple sample preparation procedure, a drop of methanol containing the respective nanoparticles was allowed to evaporate on a drop of IL and NPs spontaneously attach to the 
IL surface. Figure 1 shows SEM images illustrating the attractive forces of $\mathrm{Au}_{\mathrm{c}} \mathrm{SiO}_{2 \mathrm{~s}}$ and the repulsive forces of $\mathrm{SiO}_{2 \mathrm{c}} \mathrm{Au}_{\mathrm{s}}$ exhibited during e-beam exposure.

While the presented experiments at this point are not fully understood, understanding the interaction forces between the particles, fluid and electron beam will lead to a means of controlling NP assemblies and make new, highly organized interfacial materials.

\section{References:}

[1] Chen, Q.; Smith, J. M.; Park, J.; Kim, K.; Ho, D.; Rasool, H. I.; Zettl, A.; Alivisatos, A. P. Nano Lett. 2013, 13, 4556-4561.

[2] de Jonge, N.; Ross, F. M. Nat. Nanotechnol. 2011, 6, 695-704.

[3] Mansfeld, U.; Hoeppener, S.; Schubert, U. S. Adv. Mater. 2013, 25, 761-765.

[4] Zheng, H.; Mirsaidow, U.M.; Wang, L.-W.; Matsudaira, P. Nano Lett. 2012, 12, 5644-5648.

[5] Powers, A.S.; Liao, H.-G.; Raja, S.N.; Bronstein, N.D. Alivisatos, A.P.; Zheng, H. Nano Lett. 2017, 17, 15-20.

[6] Kim, P. Y.; Ribbe, A. E.; Russell, T. P.; Hoagland, D. A. ACS Nano 2016, 10, 6257-6264.

[7] Kim, P. Y.; Gao, Y.; Chai, Y.; Ashby, D.P.; Ribbe, A. E.; Russell, T. P.; Hoagland, D. A. ACS Nano, 2019 ASAP DOI: 10.1021/acsnano.8b08189
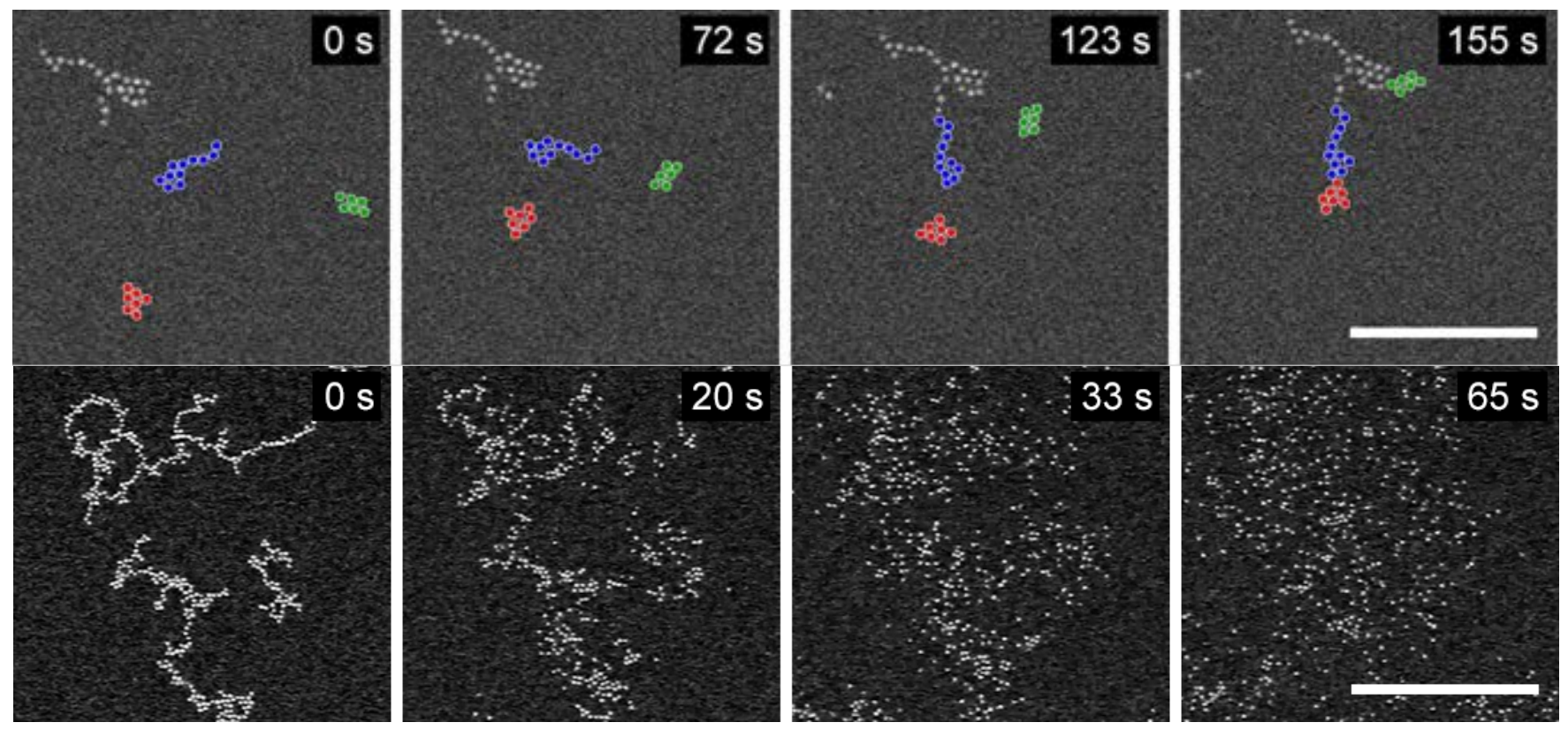

Figure 1. Still frames taken from movies showing beam induced attractive forces causing $240 \mathrm{~nm}$ $\mathrm{Au}_{\mathrm{c}} \mathrm{SiO}_{2 \mathrm{~s}}$.core-shell NPs to aggregate on [Emim][EtSO ${ }_{4}$. (top row) and repulsive forces causing $100 \mathrm{~nm}$ $\mathrm{SiO}_{2 \mathrm{c}} \mathrm{Au}_{\mathrm{s}}$ core-shell NPs to disassemble from 2D aggregates (bottom row). Both movies are taken on a FEI/ThermoFisher Magellan 400; $2 \mathrm{kV}$ and $25 \mathrm{pA}$ e-beam is applied for the former and $3 \mathrm{kV}$ and $50 \mathrm{pA}$ for the latter. Vacuum is $10^{-6}$ torr range. Scale bars are $4 \mu \mathrm{m}$. 